\title{
Thermal Analysis of a Solar Collector Absorber Plate with Microchannels
}

\author{
Oyinlola, M.A* , Shire, G.S.F. and Moss R.W \\ School of Engineering, University of Warwick, Gibbet Hill Road, Coventry, UK, CV4 7AL \\ *M.A.Oyinlola@warwick.ac.uk, +44 2476523118
}

\begin{abstract}
Experimental and theoretical analyses were carried out to investigate the absorber plate temperature distribution for compact (thin and light-weight) solar thermal collectors. An analytic model combining convective heat transfer with axial conduction in the metal plate was developed. Forced convection experiments were then performed on an instrumented metal plate with micro-channels $0.5 \mathrm{~mm} \times$ $2 \mathrm{~mm} \times 270 \mathrm{~mm}$ long, at various flow rates; the heat transfer fluid was Tyfocor ${ }^{\circledR}$ LS. Reynolds numbers were in the range $10-100$ and fluid inlet temperatures ranged from $5-60{ }^{\circ} \mathrm{C}$. The predicted plate temperature profiles from the analytic model were in close agreement with the measured profiles. Thermal entry lengths were found to be significant and resulted in slight variations at the entry portion of the plate at higher flow rates. The model was used to study the effects of varying design/operating parameters and showed that axial conduction can significantly alter the temperature profile in the plate.
\end{abstract}

Keywords: Microchannel, Absorber Plate, Solar Collector, Axial conduction, Laminar flow

\section{Introduction}

Compact solar thermal collectors are an architecturally attractive option for incorporation in buildings as an alternative to conventional flat panel or evacuated tube collectors. Several studies dedicated to improving the thermal performance of flat plate collectors have been done, some of these have focused on achieving better performance by a low temperature difference between plate and fluid [1] for example, Matrawy and Farkas [2] investigated parallel and serpentine tube arrangements in conventional sheet and tube absorber plates while Rommel and Moock [3] analytically studied solar absorbers with rectangular fluid ducts. Alvarez et al. [4] investigated a flat-plate collector with a surface contact with the heat transport fluid. The microchannel absorber plate design proposed in this study offers the potential of high heat transfer coefficient (due to the small hydraulic diameters of the channels) [5] and a fairly uniform temperature distribution in the transverse direction. These accomplish the aim of a low temperature difference between plate and fluid; it also eliminates the challenge of hotspots encountered in the conventional solar collector arrangement with tubes bonded to sheet.

The correlations and experimental results for heat transfer in conventional sized channels are well established; for fully developed laminar flow, a constant Nusselt number, whose value depends on the crosssectional geometry and boundary conditions, is expected. For example, in circular tubes with constant axial heat flux, the average Nusselt number, $\mathrm{Nu}=4.364$ while $\mathrm{Nu}=3.657$ for a constant axial wall temperature boundary condition [6]. In fully developed flow through rectangular channels, depending on the number of walls transferring heat and the aspect ratio, Nu ranges from $0.457-7.541$ for constant wall temperature, and $0.538-8.235$ for constant wall heat flux [7]. Several correlations for estimating the Nusselt number in developing flow are available, Wibulswas [8] presented correlations for non-circular ducts. Most of the results are obtained when the assumptions that the heat transfer in the duct wall is negligible and that a simplified boundary conditions (constant wall temperature or constant wall heat flux) exists.

Tuckerman and Pease [9] pioneered the study of heat transfer in microchannels over 3 decades ago by designing and testing a very compact, water-cooled integral heat sink for silicon integrated circuits. Since then, heat transfer in micro-channels has been extensively studied, however, published results are still inconsistent; some studies have found the average Nusselt number to be Reynolds number dependent in the laminar regime [10-12], some recorded lower Nusselt numbers [13-15] while some recorded higher Nusselt 
numbers [16-18]. Reviews on experimental and numerical studies of heat transfer in microchannels published by Mokrani, Bourouga, Castelain and Peerhossaini [19], Hetsroni, Mosyak, Pogrebnyak and Yarin [20], Rosa, Karayiannis and Collins [21] and Sobhan and Garimella [22] confirm the very large scatter in published results and attribute this to "scaling effects", which arise from neglecting phenomenon which are insignificant in conventional sized channels but become significant with the high channel wall surface to fluid volume ratio in microchannel flow. Some examples of these include surface roughness [14], entrance and exit effects [23, 24], axial conduction effects [15, 25], thermal boundary conditions [26], viscous dissipation effects [27], electric double layer [28] and increased measurement uncertainties [29]. Therefore, it may be difficult to apply traditional correlations to adequately describe the heat transfer in this microchannel absorber plate.

Though heat transfer in micro-channels has been extensively studied over the past 3 decades, this was largely in the context of micro-electronic components; there have been relatively few studies of micro-channel solar absorber plates. Celata's [30] definition of a microchannel as a channel whose hydraulic diameter lies between $1 \mu \mathrm{m}$ and $1 \mathrm{~mm}$ is adopted in this study. Oyinlola and Shire [31] showed that absorber plates with micro/mini-channels, instead of the conventional arrangement, were a viable option for compact solar collectors. Sharma and Diaz [32] are some of the few researchers that have published studies on solar collectors based on mini-channels; they modeled an evacuated tube collector based on mini-channels. This paper details recent analytical and experimental study into the temperature distribution in an absorber plate with microchannels. The objective of this study is to adequately model the heat transfer in this plate to allow for easy investigation of optimum design/operation combination.

\section{Nomenclature}

$\begin{array}{ll}A & \text { Longitudinal cross sectional area }\left(\mathrm{m}^{2}\right) \\ A_{p c} & \text { Ratio of top surface to channel surface (-) } \\ a & \text { Channel depth (m) } \\ b & \text { Channel width (m) } \\ c_{p} & \text { Specific heat capacity }(\mathrm{J} / \mathrm{kg} \mathrm{K}) \\ D_{h} & \text { Hydraulic diameter }(\mathrm{m}) \\ h & \text { Heat transfer coefficient }\left(\mathrm{W} / \mathrm{m}^{2} \mathrm{~K}\right) \\ k_{p} & \text { Thermal conductivity of metal }(\mathrm{W} / \mathrm{m} \mathrm{K}) \\ k_{f} & \text { Thermal conductivity of fluid }(\mathrm{W} / \mathrm{m} \mathrm{K}) \\ L & \text { Length of channel (m) } \\ \dot{m} & \text { Mass flow rate }(\mathrm{kg} / \mathrm{s}) \\ N_{c} & \text { Number of channels in plate }(-) \\ P & \text { Width of plate (m) } \\ p & \text { Channel pitch (m) } \\ Q & \text { Heat supplied (W) } \\ q & \text { Heat flux from channel walls }\left(\mathrm{W} / \mathrm{m}^{2}\right)\end{array}$

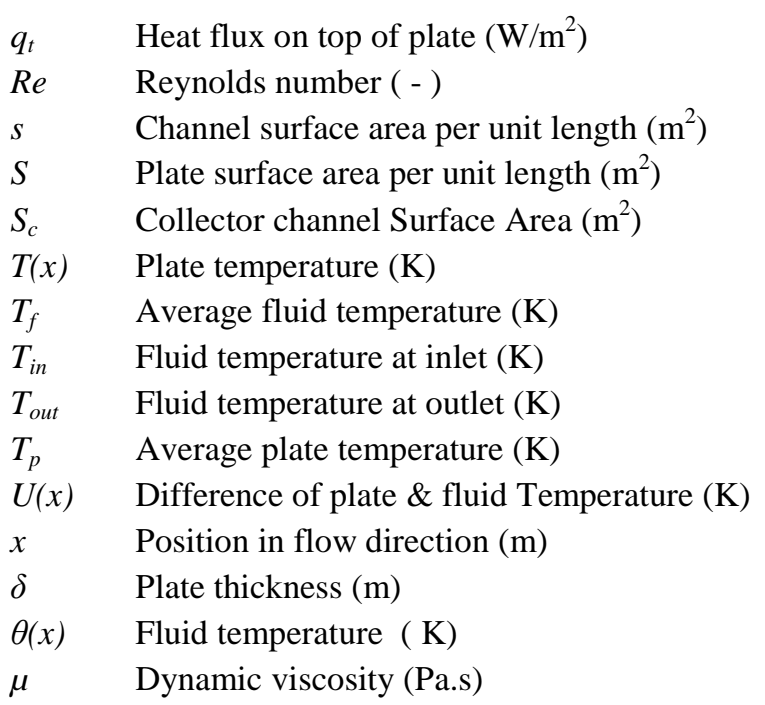

\section{Analytical Model}

The experimental apparatus (section 3) has Tyfocor passing along rectangular passages in an aluminum plate. The fourth side of the passage is formed by a cover plate that is clamped in place hard against the inter-passage ribs. A heating element supplied heat to the channeled plate. The following assumptions are made

1. The flow can be approximated as incompressible and steady state.

2. The system is perfectly insulated thus thermal losses are negligible.

3. Axial thermal conduction in the metal plate is in the flow direction only. The metal temperature is constant over a cross-section and heat transfer occurs through 4 sides of the channel.

4. The thermal properties of the plate and fluid are constant. 
5. Typical flow rates for solar collectors usually yield laminar flow with very short entry regions; therefore, the heat transfer coefficient is constant from inlet to outlet.
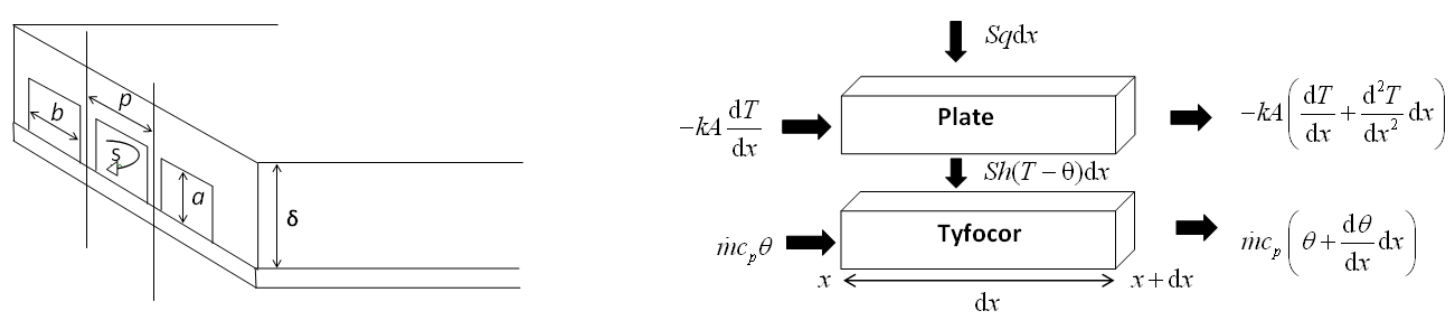

Figure 1: (a) Plate geometry and (b) Elemental volume of channel

Figure 1a shows a cross section of the microchannel plate with thickness $\delta$, at temperature $\mathrm{T}(\mathrm{x})$, subjected to a uniform heat flux $\mathrm{q}_{\mathrm{t}}$. A working fluid flows through the channel with a mass flow rate $\dot{\mathrm{m}}$ and temperature $\theta(\mathrm{x})$. For analysis purposes, the geometry was modelled as shown in Figure 1b, it shows a schematic of the heat and mass interaction in an elemental volume with length $\Delta \mathrm{x}$, a unit width and plate thickness $\delta$. For simplicity, the channel has been modeled as a flat plate having a surface area, s, equivalent to the four sides of the channel. Thermal resistance in the channel walls is negligible due to their small size $(0.5 \mathrm{~mm} \times 2 \mathrm{~mm})$. The number of channels, $\mathrm{N}_{\mathrm{c}}$ in a unit width of plate is given by

$$
N_{c}=1 / p
$$

The surface area available for heat transfer per unit length in one channel is

$$
s=2(a+b)
$$

Therefore, the total heat transfer surface area per unit length of plate is given by

$$
S=s N_{c}
$$

The ratio of top surface area to the heat transfer surface area is given by

$$
A_{p c}=\frac{p}{S}=\frac{P}{S}
$$

The heat flux from the channel walls per unit length of collector is

$$
q=q_{t} A_{p c}
$$

The cross sectional area for thermal conduction in the longitudinal direction is given by

$$
A=\delta P-\left(N_{c} a b\right)
$$

The study aims to predict the plate temperature $\mathrm{T}$ and fluid temperature $\theta$ as a function of distance $\mathrm{x}$ in the flow direction. The analysis is commenced by applying the conservation of energy principle on the elemental volume shown in Figure 1b. Taking an energy balance on the plate and simplifying yields

$$
\frac{\mathrm{d}^{2} T}{\mathrm{~d} x^{2}}-\frac{S h}{k A}(T-\theta)+\frac{S q}{k A}=0
$$

Similarly, taking an energy balance on the fluid and simplifying yields 


$$
\frac{\mathrm{d} \theta}{\mathrm{d} x}-\frac{S h}{\dot{m} c_{p}}(T-\theta)=0
$$

Equation (8) is further differentiated to make it a second order differential equation,

$$
\frac{\mathrm{d}^{2} \theta}{\mathrm{d} x^{2}}-\frac{S h}{\dot{m} c_{p}}\left(\frac{\mathrm{d} T}{\mathrm{~d} x}-\frac{\mathrm{d} \theta}{\mathrm{d} x}\right)=0
$$

Combining Equations (7) \& (9) and substituting $U=(T-\theta)$ gives the differential equation

$$
\frac{\mathrm{d}^{2} U}{\mathrm{~d} x^{2}}+\frac{S h}{\dot{m} c_{p}}\left(\frac{\mathrm{d} U}{\mathrm{~d} x}\right)-\frac{S h}{k A}(U)=-\frac{S q}{k A}
$$

This is a $2^{\text {nd }}$ order differential equation of the form $a U^{\prime \prime}+b U^{\prime}+c U=d$ whose general solution is of the form $U=C F+P I$. Solving yields $C F=A e^{\lambda_{1} x}+B e^{\lambda_{2} x}$ where $\lambda_{1}$ and $\lambda_{2}$ are the roots of the equation $a \lambda^{2}+b \lambda+c=0$ and $P I=\frac{q}{h}$

$U=A e^{\lambda_{1} x}+B e^{\lambda_{2} x}+\frac{q}{h}$

Re-arranging Equation(8), gives $\frac{\mathrm{d} \theta}{\mathrm{d} x}=\frac{S h}{\dot{m} c_{p}}(T-\theta)$, therefore

$$
\begin{aligned}
& \theta(x)=\int \frac{\mathrm{d} \theta}{\mathrm{d} x} \mathrm{~d} x=\int \frac{S h}{\dot{m} c_{p}} U d x=\left[\frac{S h}{\dot{m} c_{p}}\left(\frac{A}{\lambda_{1}}\left(e^{\lambda_{1} x}-1\right)+\frac{B}{\lambda_{2}}\left(e^{\lambda_{2} x}-1\right)\right)+\frac{S q}{\dot{m} c_{p}} x\right]_{0}^{X} \\
& T(x)=\left(A e^{\lambda_{1} x}+B e^{\lambda_{2} x}+\frac{q P}{S h}\right)+\theta(x)
\end{aligned}
$$

The constants $A$ and $B$ are obtained by using the boundary conditions that $\frac{\mathrm{d} T}{\mathrm{~d} x}=0$ at at $x=0$ and $x=\mathrm{L}$ (since the plate is perfectly insulated at both ends). This implies that at both ends

$$
\frac{\mathrm{d} U}{\mathrm{~d} x}=-\frac{\mathrm{d} \theta}{\mathrm{d} x}
$$

Differentiating Equations (12) and (13) then inserting into Equation (14) yields

At $\mathrm{x}=0$

$$
A\left(\lambda_{1}+\frac{S h}{\dot{m} c_{p}}\right)+B\left(\lambda_{2}+\frac{S h}{\dot{m} c_{p}}\right)=-\frac{S q}{\dot{m} c_{p}}
$$

And at $\mathrm{x}=\mathrm{L}$ 


$$
A\left(\lambda_{1} e^{\lambda_{1} L}+\frac{S h}{\dot{m} c_{p}} e^{\lambda_{1} L}\right)+B\left(\lambda_{2} e^{\lambda_{2} L}+\frac{S h}{\dot{m} c_{p}} e^{\lambda_{2} L}\right)=-\frac{S q}{\dot{m} c_{p}}
$$

Equations (15) and (16) can be solved simultaneously to get the constants A and B.

\section{Experimental Apparatus}

\subsection{Description of the experimental system}

The test rig was made up of two $340 \times 240 \times 10 \mathrm{~mm}$ aluminum slabs $-\mathrm{a}$ "top" and "bottom" piece, with a thinner $(3 \mathrm{~mm})$ channel plate sandwiched between them, as shown in Figure 2. This arrangement allowed a variety of relatively simple channel plates to be tested without each needing its own inlet and outlet connections. A self-adhesive $60 \mathrm{~W}$ heater mat was mounted on the top slab. The rig was insulated with a custom-built Polyisocyanurate (PIR) box. The channels and manifolds were designed as a Z type heterogeneous ladder with two scale resistance; from the model presented by Tondeur, Fan, Commenge and Luo [33], the mal distribution in the channels is expected to be less than $20 \%$. The absorber plate, shown in Figure 4, had sixty micro-channels $0.5 \mathrm{~mm} \times 2 \mathrm{~mm} \times 270 \mathrm{~mm}$ long spaced $1 \mathrm{~mm}$ apart ( $3 \mathrm{~mm}$ pitch). The thermal working fluid was Tyfocor ${ }^{\circledR}$ LS, a propylene glycol-based heat transfer fluid for solar collectors. This was supplied at constant temperature and flow rate by a circulating bath. The fluid inlet temperatures and flow rates used for the experiment are shown in Table 1. The Reynolds numbers from all flow rates indicate laminar flow.

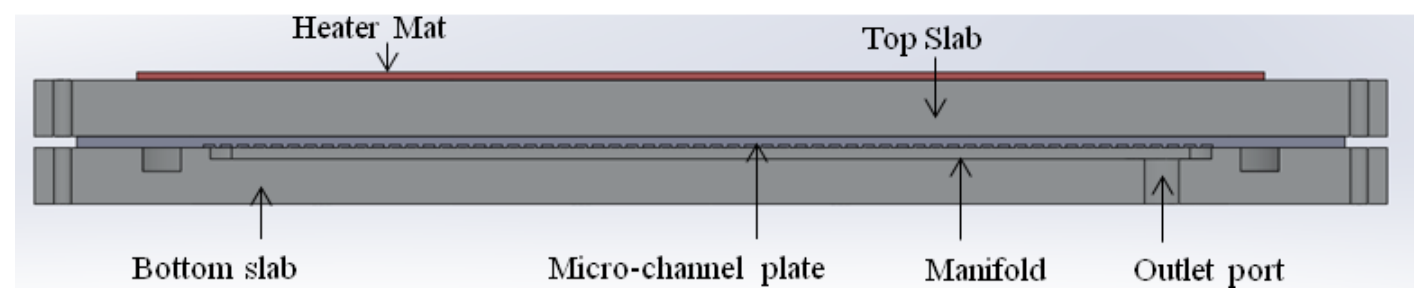

Figure 2: Cross section of test rig
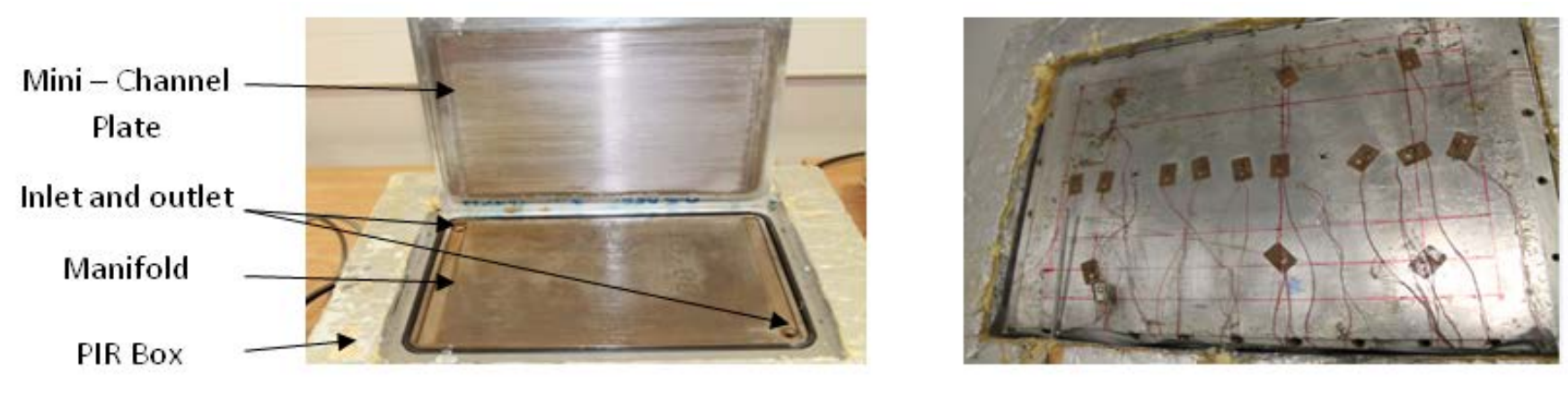

Figure 3: (a) Inner face of Test Rig (b) Thermocouple arrangement on plate 


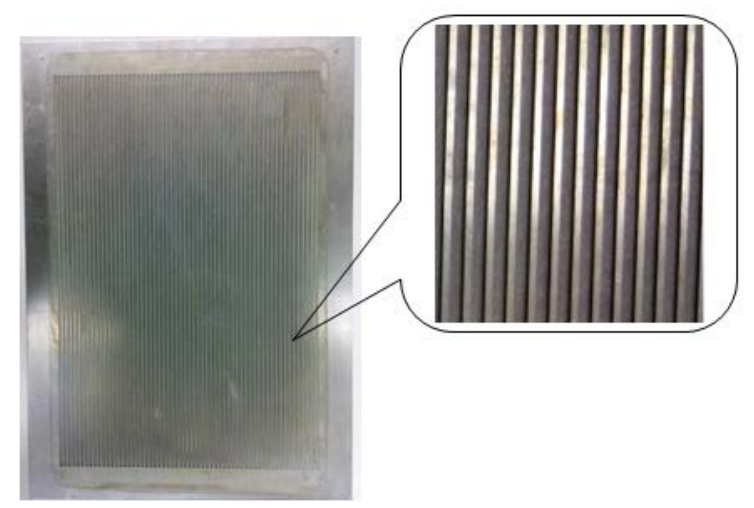

Figure 4: Micro-channels on plate

Temperatures of the plate at different points $\left(\mathrm{T}_{\mathrm{pi}}\right)$, fluid at inlet $\left(\mathrm{T}_{\mathrm{in}}\right)$ and fluid at outlet $\left(\mathrm{T}_{\text {out }}\right)$, were measured using Type $\mathrm{T}$ thermocouples. Some thermocouples were fixed on the absorber plate using fiber glass thermal attachment pads as shown in Figure $3 \mathrm{~b}$ while one each was placed inside the inlet and outlet ports after elbow fittings (for fluid mixing) to allow accurate readings of bulk fluid temperature. The flow rate ( $\dot{\mathrm{m}})$ and pressure drop $(\Delta \mathrm{p})$ were measured using a Coriolis mass flow meter and a differential pressure sensor respectively. All the measured quantities were logged with a 16-bit National Instruments data acquisition system via Labview. Thermocouples were connected through a SCXI-1102 thermocouple interface board. Signals were sampled at $2 \mathrm{~Hz}$, signal quality was studied using an oscilloscope to ensure they were clean and free from interference. At a given flow rate, the temperatures reached steady state after approximately 1015 minutes. The enthalpy change of the fluid was used to calculate heat flux and the power consumed by the heater mat was measured using a voltmeter and ammeter; these values were within $10 \%$ of the enthalpy change of the fluid between inlet and outlet. Figure 5 and Figure 6 respectively show the schematic of the experimental setup and the actual apparatus.

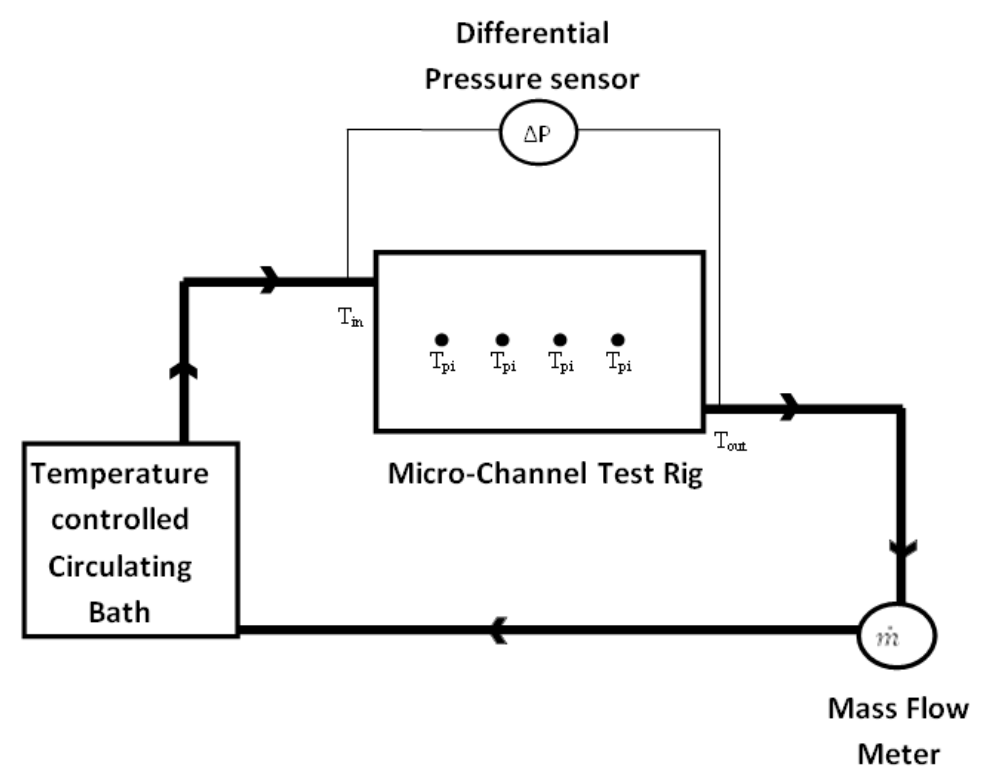

Figure 5: General arrangement of experiment 


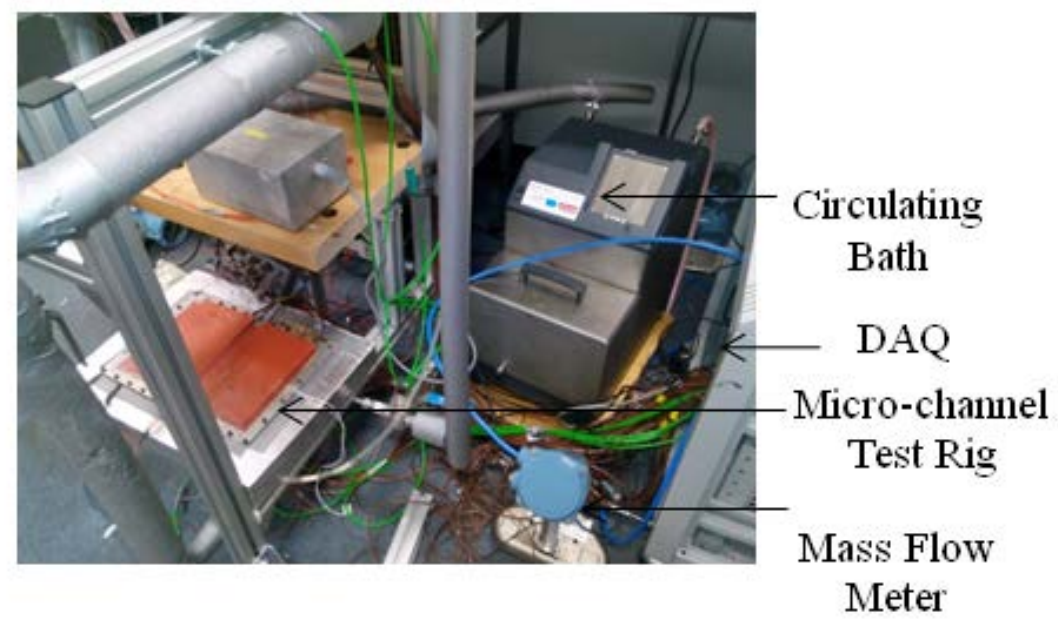

Figure 6: Actual experimental setup

\subsection{Data Reduction}

The measured quantities used were an average of 200 readings after reaching steady state. The parameters below were calculated using these averages.

Reynolds number, $R e=\left(\frac{\dot{m}}{a b N_{c}}\right) \frac{D_{h}}{\mu}$

Mean plate temperature, $T_{p}=\frac{\sum_{i=1}^{n} T_{p i}}{n}$

Mean fluid temperature, $T_{f}=\frac{T_{\text {in }}+T_{\text {out }}}{2}$

Collector channel surface area, $S_{c}=2 N_{c} L(a+b)$

Heat transferred to fluid, $Q=\dot{m} C_{p}\left(T_{\text {out }}-T_{\text {in }}\right)$

Heat transfer coefficient, $h=\frac{Q}{S_{c}\left(T_{p}-T_{f}\right)}$

Thermal entry length, $L_{t}=0.05 \operatorname{RePr} D_{h}$

Table 1: Details of experimental runs

\begin{tabular}{lllll}
\hline Run & $T_{\text {in }}\left({ }^{\circ} \mathrm{C}\right)$ & $\dot{m}(\mathrm{~g} / \mathrm{s})$ & $R e$ & $L_{t} / L(\%)$ \\
\hline $\mathbf{1}$ & 5.9 & 12.3 & 15.9 & 21.3 \\
$\mathbf{2}$ & 5.9 & 11.1 & 14.5 & 19.2 \\
$\mathbf{3}$ & 6.1 & 9.2 & 12.2 & 15.9 \\
$\mathbf{4}$ & 6.3 & 7.2 & 9.9 & 12.5 \\
$\mathbf{5}$ & 6.5 & 5.4 & 7.7 & 9.3 \\
$\mathbf{6}$ & 7.0 & 3.6 & 5.6 & 6.2 \\
$\mathbf{7}$ & 7.7 & 2.1 & 3.6 & 3.6 \\
$\mathbf{8}$ & 20.4 & 18.0 & 47.6 & 31.1 \\
\hline
\end{tabular}




\begin{tabular}{lllll}
\hline $\mathbf{9}$ & 20.3 & 15.3 & 40.6 & 26.5 \\
$\mathbf{1 0}$ & 20.3 & 12.7 & 33.8 & 22.0 \\
$\mathbf{1 1}$ & 20.3 & 10.2 & 27.3 & 17.6 \\
$\mathbf{1 2}$ & 20.3 & 8.0 & 21.6 & 13.8 \\
$\mathbf{1 3}$ & 20.4 & 5.7 & 15.6 & 9.8 \\
$\mathbf{1 4}$ & 20.5 & 3.5 & 9.9 & 6.0 \\
$\mathbf{1 5}$ & 39.9 & 21.4 & 115.0 & 36.4 \\
$\mathbf{1 6}$ & 39.9 & 18.6 & 100.0 & 31.6 \\
$\mathbf{1 7}$ & 39.9 & 15.9 & 85.7 & 27.1 \\
$\mathbf{1 8}$ & 39.9 & 13.2 & 71.3 & 22.5 \\
$\mathbf{1 9}$ & 39.8 & 10.4 & 56.3 & 17.7 \\
$\mathbf{2 0}$ & 39.7 & 7.6 & 41.3 & 12.9 \\
$\mathbf{2 1}$ & 39.5 & 4.9 & 26.9 & 8.3 \\
$\mathbf{2 2}$ & 59.8 & 23.0 & 203.9 & 38.7 \\
$\mathbf{2 3}$ & 59.6 & 14.3 & 126.9 & 24.1 \\
$\mathbf{2 4}$ & 59.1 & 6.0 & 53.4 & 10.1 \\
$\mathbf{2 5}$ & 59.8 & 23.0 & 203.9 & 38.7 \\
$\mathbf{2 6}$ & 59.6 & 14.3 & 126.9 & 24.1 \\
$\mathbf{2 7}$ & 59.1 & 6.0 & 53.4 & 10.1 \\
$\mathbf{2 8}$ & 59.1 & 6.0 & 53.4 & 10.1 \\
\hline
\end{tabular}

\subsection{Uncertainty}

The Data Acquisition system has a function for calibrating all channels. This procedure compensates for the inaccuracies in the whole measurement system. The thermocouples were bonded together, put in the bath and calibrated at a number of temperatures to match bath temperature readout. Voltages from the mass flow meter were calibrated to match its display readout while the differential pressure sensor was calibrated to match a hand held manometer. The mass flow meter was also checked by timing flow into a measuring cylinder.

After calibration, the maximum deviation observed in each sensor was taken as the instrument's uncertainty. Uncertainties in geometric parameters were estimated using high precision measuring instruments as well as manufacturers' specifications. The observed maximum deviations were used to estimate the uncertainties in the calculated values, assuming that the deviations in each term were uncorrelated. For example, equation (24) [34] was used to estimate the uncertainty in the heat transfer coefficient. Table 2 gives the details of the uncertainty of some measured and calculated parameters.

$$
\omega_{h}=h\left[\left(\frac{\omega_{Q}}{Q}\right)^{2}+\left(\frac{\omega_{A}}{A}\right)^{2}+\left(\frac{\omega_{\Delta T_{p f}}}{\Delta T_{p f}}\right)^{2}\right]^{1 / 2}
$$

Table 2: Uncertainties in measurement

\begin{tabular}{lll}
\hline S/No & Parameter & Uncertainty \\
\hline $\mathbf{1}$ & $\mathrm{a}, \mathrm{b}$ & $0.05 \mathrm{~mm}$ \\
$\mathbf{2}$ & $\mathrm{D}_{\mathrm{h}}$ & $0.11 \mathrm{~mm}$ \\
& $\mathrm{~S}$ & $46 \mathrm{~mm}^{2}$ \\
& $\mathrm{Q}$ & $3 \%$ \\
$\mathbf{3}$ & $\mathrm{T}_{\text {in }}, \mathrm{T}_{\text {out }}, \mathrm{T}_{\mathrm{pi}}$ & $0.1^{\circ} \mathrm{C}$ \\
$\mathbf{4}$ & $\dot{m}$ & $0.15 \mathrm{~g} / \mathrm{s}$ \\
$\mathbf{5}$ & $\mathrm{T}_{\mathrm{f}}$ & $0.14^{\circ} \mathrm{C}$ \\
$\mathbf{6}$ & $\mathrm{T}_{\mathrm{p}}$ & $0.2^{\circ} \mathrm{C}$ \\
$\mathbf{7}$ & $\mathrm{h}$ & $10 \%$ \\
$\mathbf{8}$ & $\mathrm{Re}$ & $10 \%$ \\
\hline
\end{tabular}




\section{Results and Discussion}

\subsection{Comparing analytical and experimental results}

Figure 7, Figure 8 and Figure 9 compare the experimental data points with the model at various fluid inlet temperatures and flow rates. In each case, the simulation was based on the fluid inlet temperature, heat flux and average heat transfer coefficient. It can be noted that the fluid profile intersects the measured inlet and outlet temperatures and the curve becomes more linear with flow rate. In Figure 7, the measured profile matches predicted profile within experimental uncertainty bounds; however, in Figure 8 and Figure 9, which have higher flow rates, the predicted and measured plate temperature profiles differ. Looking at Figure 9, the predicted curve divides the data points into two halves, which indicate a variation in the local heat transfer coefficient in the flow direction. Comparing Figure 8 and Figure 9 shows that this difference between measured and predicted plate temperature profile increases with flow rate. This trend suggests that the difference in temperature profile can be attributed to entrance effects on the heat transfer coefficient because the thermal entry length (23), which increases with flow rate, increases the local heat transfer coefficient .These effects seem to be significant and hence cannot be neglected when estimating the average heat transfer coefficient. Assumption (4) in section 2 is therefore not valid when the channel length is short.

It should be noted that the average heat transfer coefficients estimated from measured quantities are much lower than expected. This was also observed by some other researchers including Dixit and Ghosh [13], Peng, Peterson and Wang [10] and Wu and Cheng [35] who performed experiments at low Reynolds number. The calculated average heat transfer coefficients show a Reynolds number dependence behaving in a similar fashion to the correlations for microchannel heat transfer given by Choi, Barren and Warrington [12], Peng and Peterson [11] and Peng, Peterson and Wang [10].

These low heat transfer coefficients might also suggest that heat is not transferred from all four walls equally [7] or a mixed boundary condition may exist on the channel walls [23].

Figure 10 shows the measured plate temperature profiles. A slight variation in the transverse direction is observed which can be neglected because it is within the bounds of experimental error. This supports assumption (1) of axial conduction in the longitudinal direction only. Similarly, it suggests that the flow rate and heat transfer coefficient are similar transversely. However, in wider plates, further manifold design considerations, like that presented by [33] will need to be implemented.

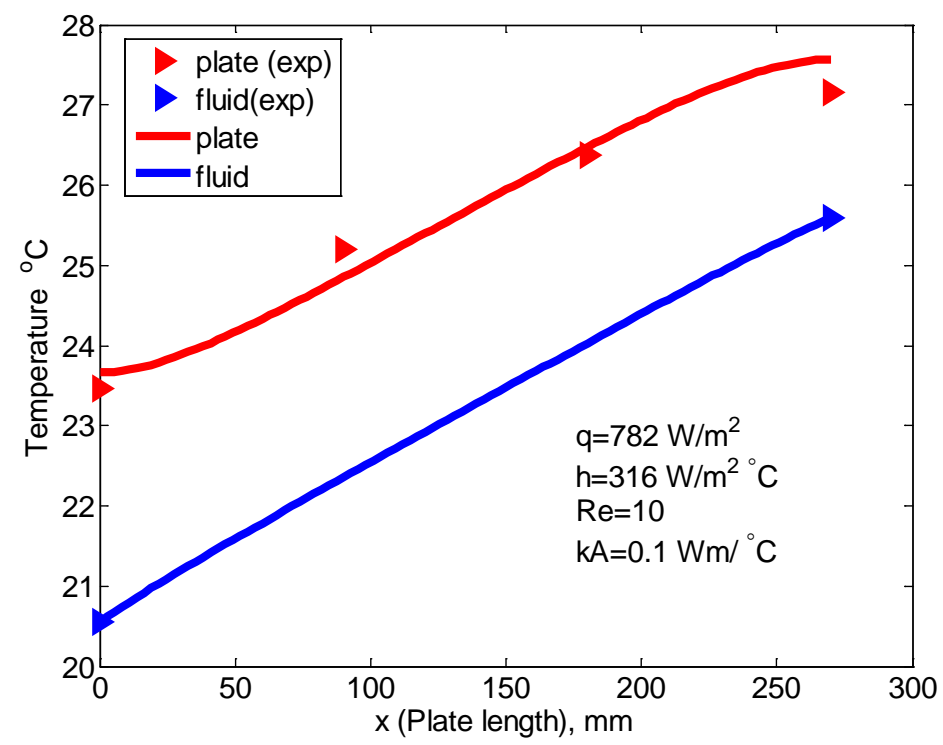

Figure 7: Comparing analytic and experimental results $\left(\mathrm{Re}=10, \mathrm{~T}_{\mathrm{in}}=20.5^{\circ} \mathrm{C}\right)$ 


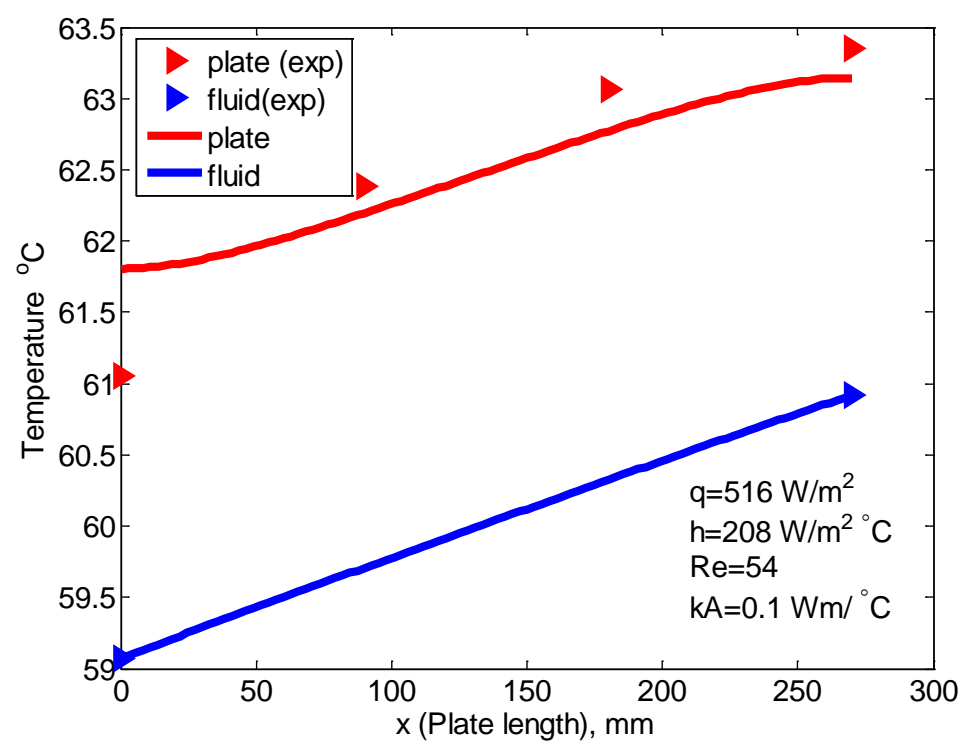

Figure 8: Comparing analytic and experimental results $\left(\mathrm{Re}=54, \mathrm{~T}_{\mathrm{in}}=59^{\circ} \mathrm{C}\right)$

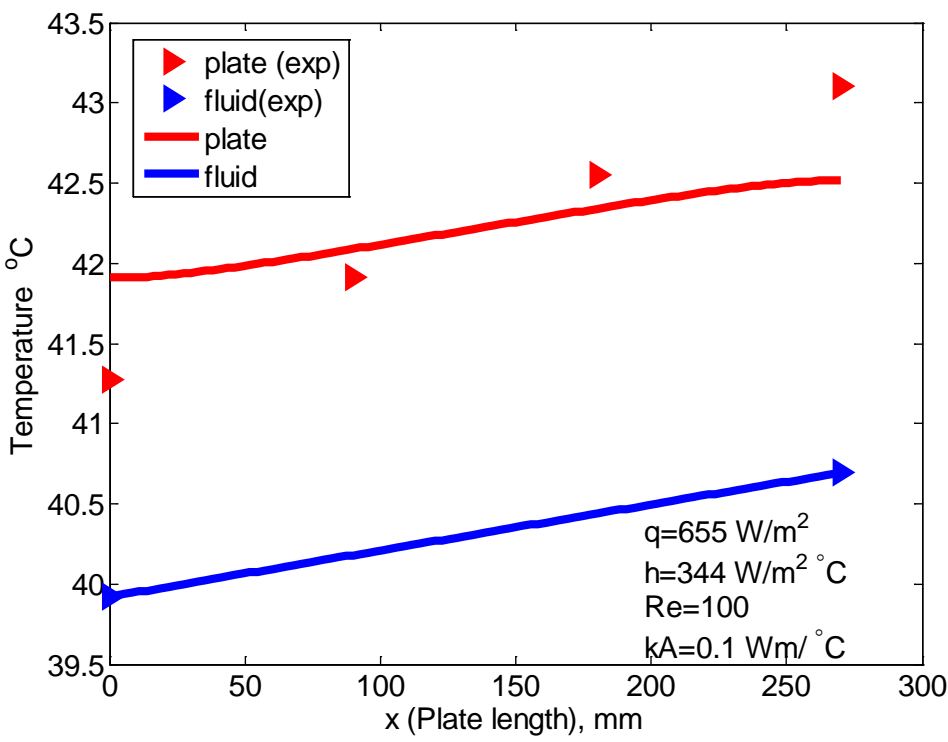

Figure 9: Comparing analytic and experimental results $\left(\mathrm{Re}=100, \mathrm{~T}_{\mathrm{in}}=40^{\circ} \mathrm{C}\right)$ 


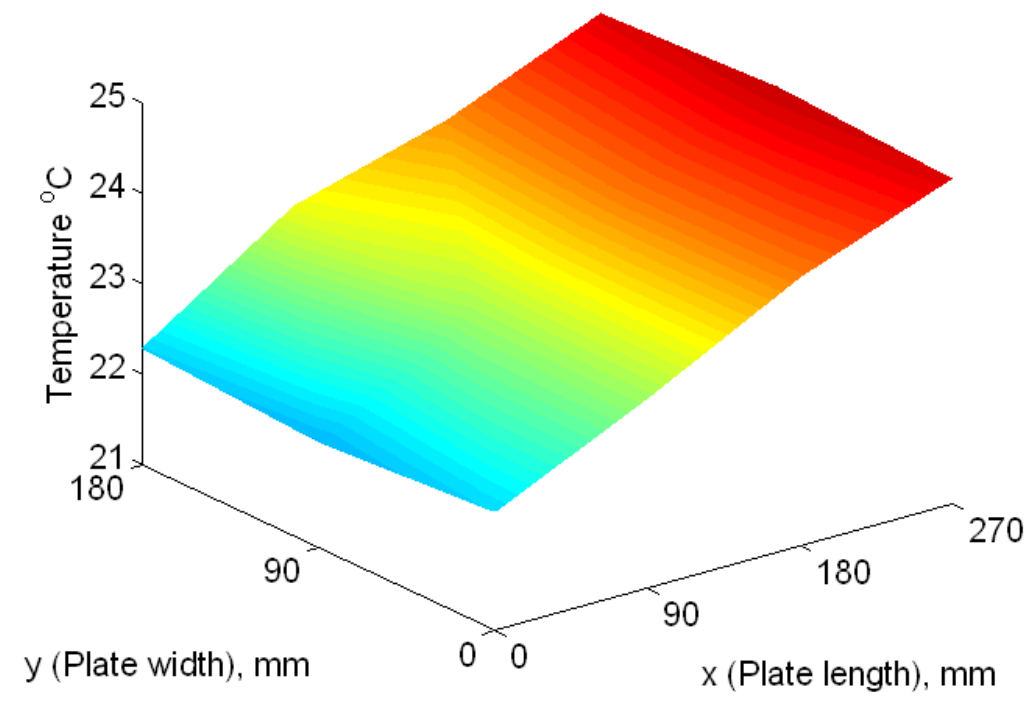

Figure 10: Measured temperature distribution in metal plate

\subsection{Design/operating parameters}

Equations (12) and (13) were used to plot the fluid and plate temperature profiles (referred to fluid inlet temperature) for nominal flow rates, heat transfer coefficients and rates of axial thermal conduction, for Tyfocor flowing in a $1 \mathrm{~m}^{2}$ collector absorber plate whose channel walls have a heat flux of $\mathrm{q}=1000 \mathrm{~W} / \mathrm{m}^{2}$ and total surface area of $1.665 \mathrm{~m}^{2}$. The graphs for these plots are shown in Figure 11 - Figure 13 .

\subsubsection{Flow rate}

The range of flow rates plotted, 0.02 and $0.2 \mathrm{~kg} / \mathrm{s}$, corresponding to $10<\mathrm{Re}<93$, which covers the economical operating range of an actual collector; these flow rates indicate that the thermal entry length is negligible and the flow can be approximated as thermally fully developed.

As expected, Figure 11 shows that the fluid and plate temperature profile changes with the change in flow rate. The axial conduction effects can be observed at both ends of the plate; they become less significant as the flow rate increases. Apart from at the ends, the temperature difference between fluid and plate is almost constant over most of the length, which is what is expected in a constant heat flux boundary condition.

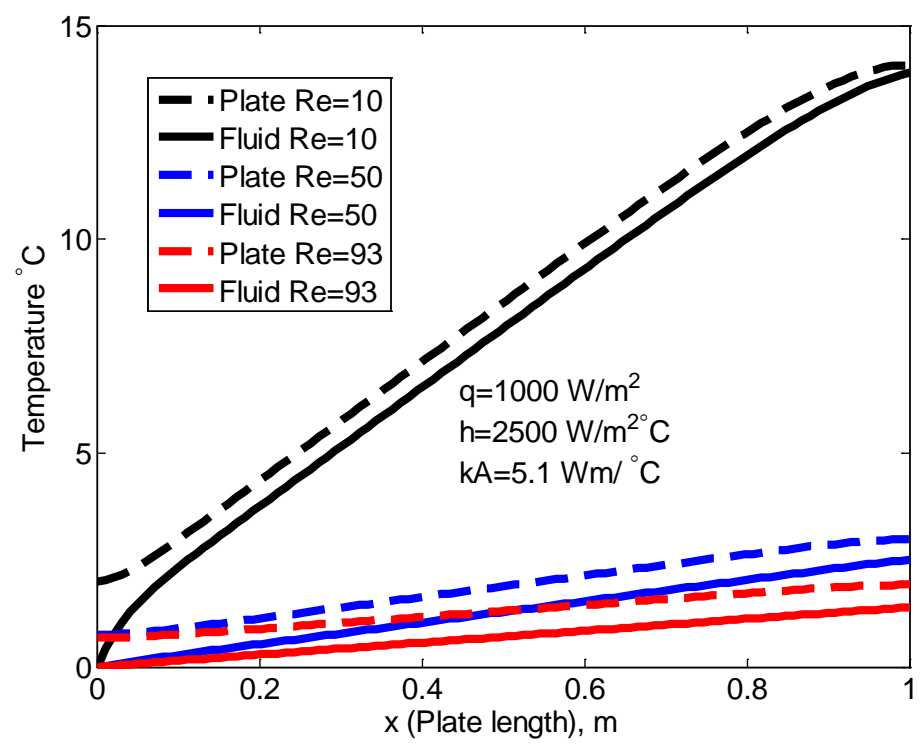

Figure 11: Temperature profile of fluid and metal plate at various flow rates 


\subsubsection{Heat Transfer coefficient}

As stated earlier, several correlations/results have been published for laminar flow heat transfer in rectangular macro and micro channels with value varying depending on the aspect ratio and the boundary conditions. Figure 12 shows a plot covering the different possible heat transfer coefficients that can be expected from the channels $\left(500 \mathrm{~W} / \mathrm{m}^{2}{ }^{\circ} \mathrm{C}-4500 \mathrm{~W} / \mathrm{m}^{2}{ }^{\circ} \mathrm{C}\right)$. The graph shows that the fluid temperature profile remains unchanged, therefore increasing the heat transfer coefficient has no effect on the fluid temperature profile, but reduces the temperature difference between metal plate and fluid. Achieving high heat transfer coefficients will therefore reduce the thermal losses from the collector to the ambient.

The heat transfer coefficient, h, has been assumed constant because typical flow rates for solar collectors usually yield laminar flow with very short entry regions. The differential equation (10) can however be solved numerically (in Matlab for instance) with an arbitrary heat transfer coefficient profile $\mathrm{h}(\mathrm{x})$, which might be chosen based on entry length effect correlations or boundary condition Nusselt number.

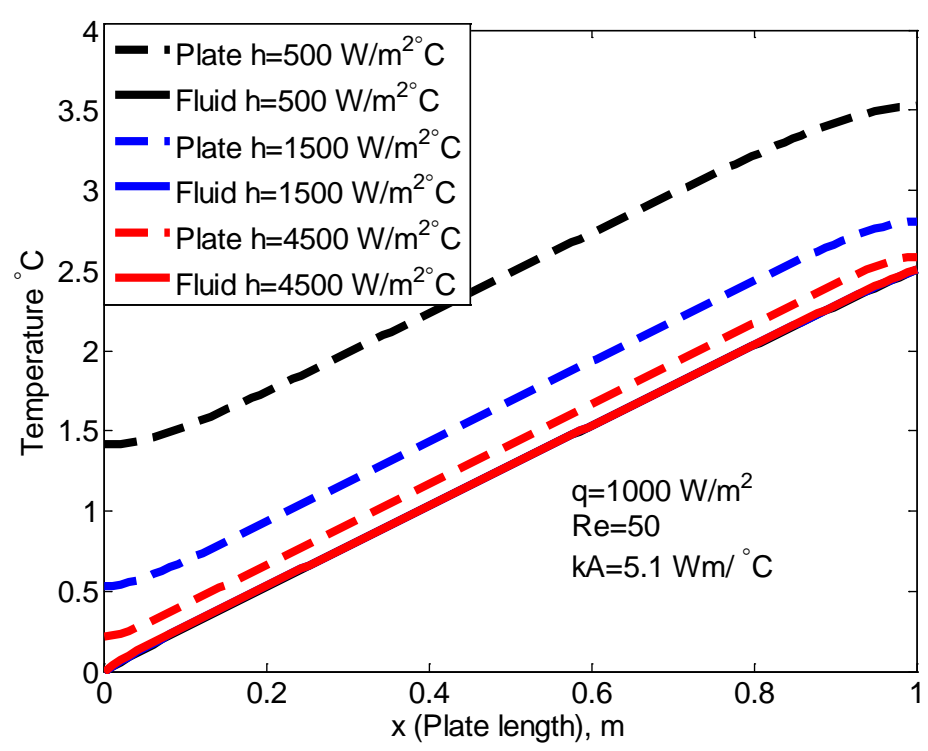

Figure 12: Temperature profile of fluid and metal plate at various heat transfer coefficients

\subsubsection{Axial Thermal conduction}

Figure 13 shows the variation of fluid and plate temperature profile along the length for varying values of $\mathrm{k}_{\mathrm{p}} \mathrm{A}$. The range plotted cover actual design parameters; $\mathrm{k}_{\mathrm{p}} \mathrm{A}=0.1-9 \mathrm{Wm} /{ }^{\circ} \mathrm{C}$ covers making the plate from a $3 \mathrm{~mm}$ thick PTFE sheet to a $20 \mathrm{~mm}$ thick copper sheet. It can be observed that the fluid profile varies by less than $0.1^{\circ} \mathrm{C}$ while the plate temperature profile varies noticeably in the initial and final $10 \%$ regions. This variation can be quite significant for shorter channels. It also indicates that the sides of the plate need to be insulated properly to minimize the heat loss. 


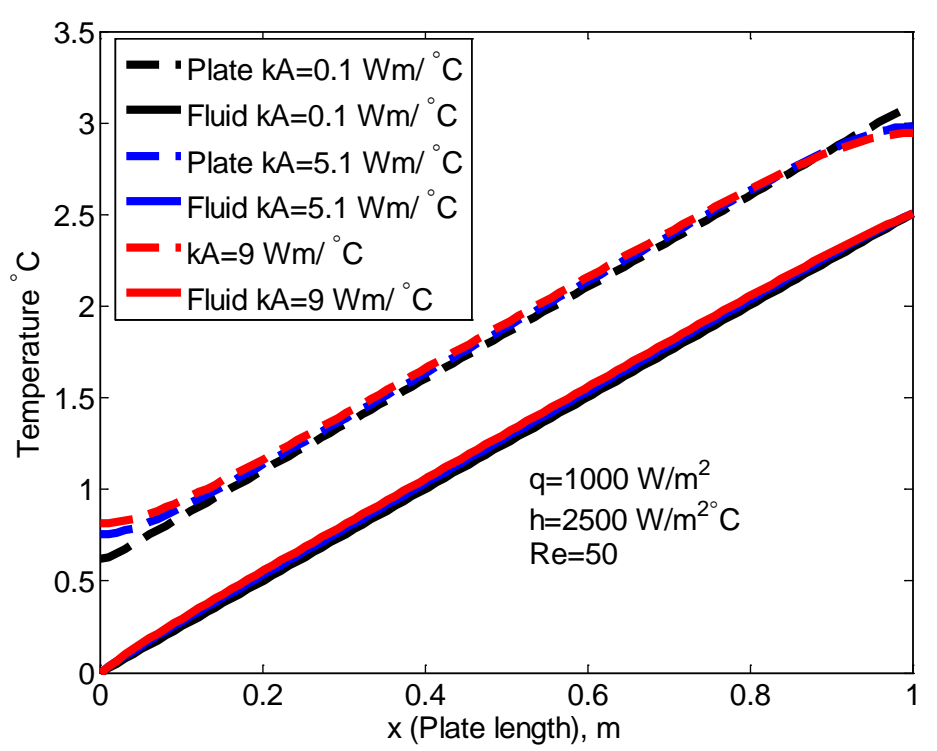

Figure 13: Temperature profile of fluid and metal plate at various rates of axial thermal conductivity

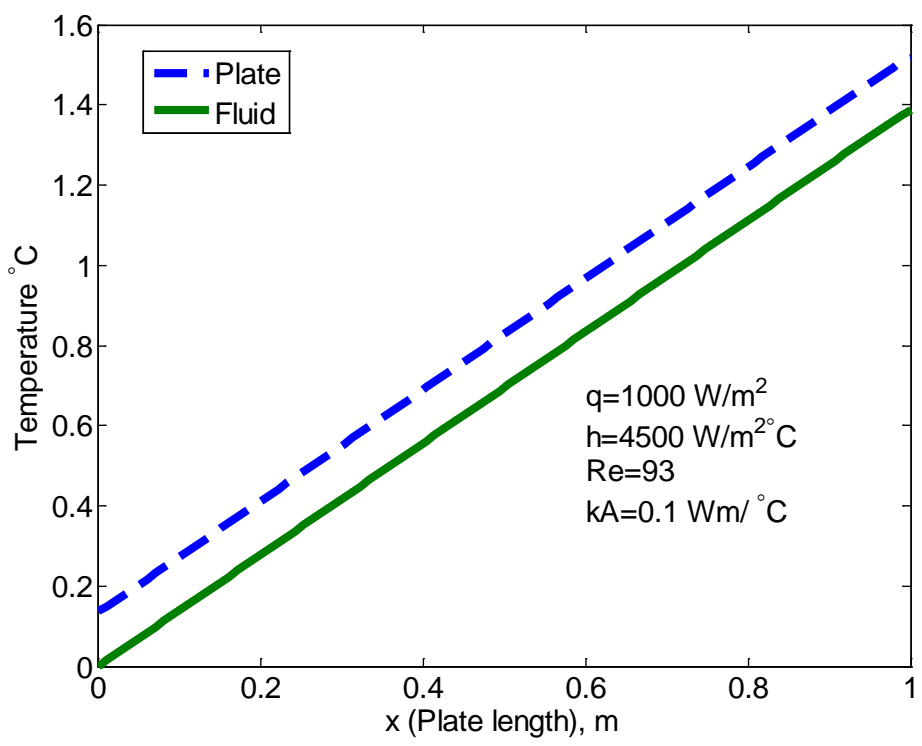

Figure 14: Temperature profile of fluid and metal plate for the upper extreme case 


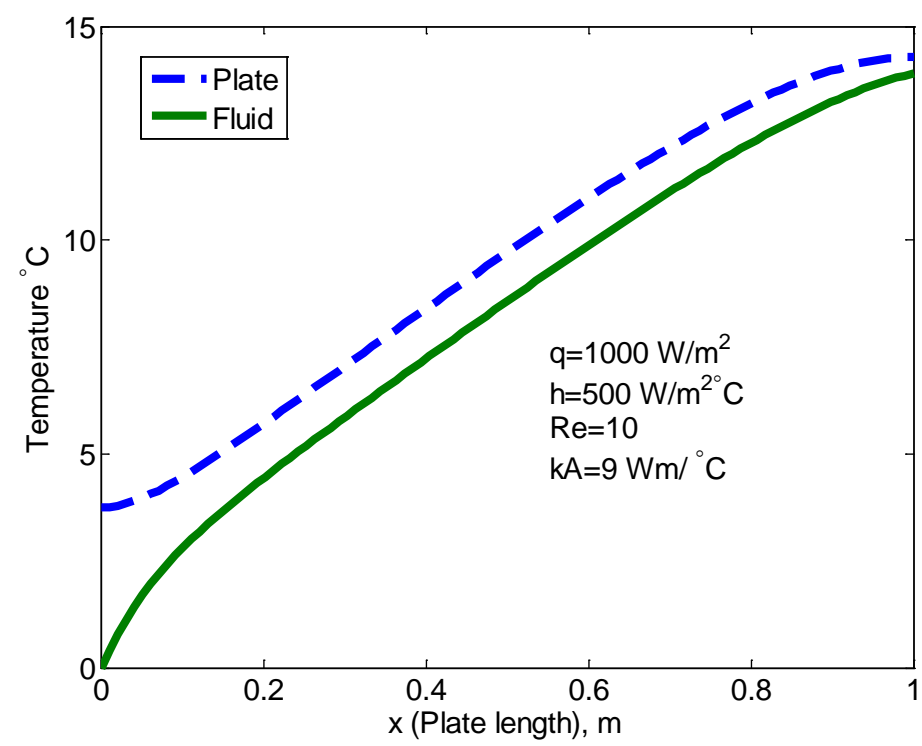

Figure 15: Temperature profile of fluid and metal plate for the lower extreme case

Figure 14 and Figure 15 show the plate and fluid temperature profile for two cases. From Figure 14, it can be observed that axial thermal conduction is negligible and the difference between fluid and plate temperature profiles is constant. This is the expected trend in conventional laminar forced convection heat transfer with a constant heat flux boundary; this signifies that if axial conduction is negligible, conventional heat transfer analysis will suffice. Figure 15 shows a combination of a constant heat flux wall boundary condition and isothermal wall boundary condition. A trend consistent with a constant temperature wall boundary condition is observed at the inlet and exit while the constant heat flux condition is observed at the middle section of the plate. This signifies that when axial conduction is significant, the boundary condition at the walls may be mixed.

Figure 16 compares the temperature difference between plate and fluid (U) at two extreme cases. It can be observed that when the axial conduction is significant, $U$ develops an 's' shaped curve. This flattens out with reduction in axial conduction until it approximates the expected straight line for constant heat flux wall boundary condition. It also indicates that the length of channel can make the axial conduction more pronounced in shorter channels.

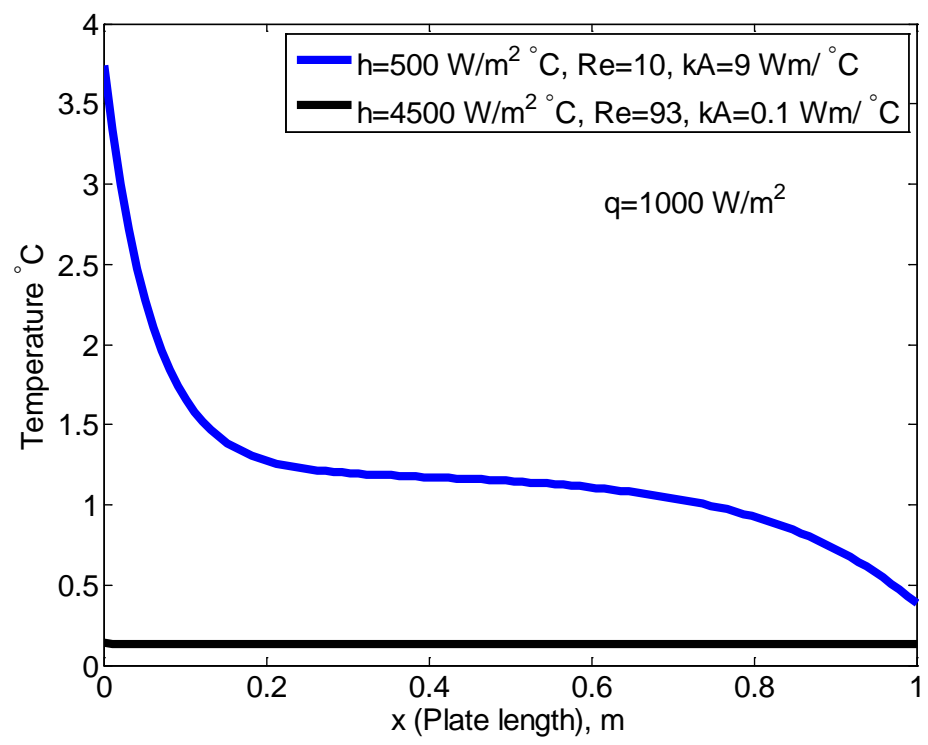

Figure 16: Temperature difference between plate and fluid (U) for the two extreme cases 


\section{Conclusion}

An analytic model has been developed to predict the fluid and plate temperature profile of a microchannel absorber plate for solar thermal collectors. The model was compared to experimental data and showed good agreement at low flow rates. It was observed that entry length had significant effects on the heat transfer coefficient; the average heat transfer coefficient used in the model caused the profiles to differ at higher flow rates when the entry length was significant. The Nusselt numbers for fully developed laminar flow are constant (not function of Re) whereas in an entry length region, the boundary layer is thinner and the Nusselt number higher. Since the entry length region develops further at higher Reynolds number, there is an advantage in advancing towards a high (laminar) Reynolds number to obtain a longer entry length region. Higher Reynolds number can be achieved by pumping the fluid at higher velocities; the increased mass flow rate then also reduces the overall fluid temperature rise, albeit at the expense of increased pumping power. The alternative, to increase the hydraulic diameter may lead to a reduction in the heat transfer coefficient

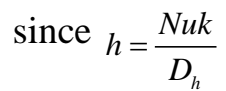

The results show that the effect of axial thermal conduction in the plate can significantly alter the temperature profile of the metal plate and result in a mixed wall boundary condition at the wall. The ability to predict the 's' shaped distribution of metal temperature has implications for the design and interpolation of experiments, for example, when using thermocouples to measure plate temperature, the thermocouple position can have significant impact on the experimental results. It might also need to be considered during the design of microchannel systems for cooling electronic devices.

\section{Acknowledgments}

This research used equipment through the Science City Energy project, part funded by the European Regional Development Fund, ERDF.

\section{References}

[1] Z. Chen, S. Furbo, B. Perers, F. J., E. Andersen, Efficiencies of flat plate solar collectors at different flow rates, in: 1st International Conference on Solar Heating International Conference on Solar Heating and Cooling for Buildings and Industry, Energy Procedia, 2012, pp. 65-72.

[2] K.K. Matrawy, I. Farkas, Comparison study for three types of solar collectors for water heating, Energy Conversion and Management, 38 (1997) 861-869.

[3] M. Rommel, W. Moock, Collector efficiency factor F' for absorbers with rectangular fluid ducts contacting the entire surface, Solar Energy, 60 (1997) 199-207.

[4] A. Alvarez, O. Cabeza, M.C. Muñiz, L.M. Varela, Experimental and numerical investigation of a flat-plate solar collector, Energy, 35 (2010) 3707-3716.

[5] S.G. Kandlikar, Heat transfer and fluid flow in minichannels and microchannels, Elsevier, Amsterdam, Netherlands; San Diego, CA; Oxford, UK, 2006.

[6] J.P. Holman, Heat transfer, McGraw Hill Higher Education, Boston, [Mass.], 2010.

[7] R.K. Shah, A.L. London, Laminar flow forced convection in ducts : a source book for compact heat

exchanger analytical data, Academic Press, New York, 1978.

[8] P. Wibulswas, Laminar-flow heat-transfer in non-circular ducts, in, University of London, 1966.

[9] D.B. Tuckerman, R.F.W. Pease, High-performance heat sinking for VLSI, IEEE Electron Device Lett. IEEE Electron Device Letters, 2 (1981) 126-129.

[10] X. Peng, G. Peterson, B. Wang, Heat transfer characteristics of water flowing through microchannels, Experimental Heat Transfer An International Journal, 7 (1994) 265-283.

[11] X.F. Peng, G.P. Peterson, Convective heat transfer and flow friction for water flow in microchannel structures, International Journal of Heat and Mass Transfer, 39 (1996) 2599-2608.

[12] S.B. Choi, R.R. Barren , R.Q. Warrington, Fluid flow and heat transfer in micro-tubes, ASME DSC (1991) 89-93. 
[13] T. Dixit, I. Ghosh, Low Reynolds number thermo-hydraulic characterization of offset and diamond minichannel metal heat sinks, Experimental Thermal and Fluid Science, 51 (2013) 227-238.

[14] W. Qu, G.M. Mala, D. Li, Heat transfer for water flow in trapezoidal silicon microchannels, International Journal of Heat and Mass Transfer, 43 (2000) 3925-3936.

[15] G. Gamrat, M. Favre-Marinet, D. Asendrych, Conduction and entrance effects on laminar liquid flow and heat transfer in rectangular microchannels, International Journal of Heat and Mass Transfer, 48 (2005) 2943-2954.

[16] T.M. Adams, S.I. Abdel-Khalik, S.M. Jeter, Z.H. Qureshi, An experimental investigation of single-phase forced convection in microchannels, International Journal of Heat and Mass Transfer, 41 (1998) 851-857.

[17] G.P. Celata, M. Cumo, M. Guglielmi, G. Zummo, Experimental investigation of hydraulic and singlephase heat transfer in 0.130-mm capillary tube, Microscale Thermophysical Engineering, 6 (2002) 85-97. [18] A. Bucci, G.P. Celata, M. Cumo, E. Serra, G. Zummo, Water single-phase fluid flow and heat transfer in capillary tubes, in: ASME 2003 1st International Conference on Microchannels and Minichannels, American Society of Mechanical Engineers, 2003, pp. 319-326.

[19] O. Mokrani, B. Bourouga, C. Castelain, H. Peerhossaini, Fluid flow and convective heat transfer in flat microchannels, International Journal of Heat and Mass Transfer, 52 (2009) 1337-1352.

[20] G. Hetsroni, A. Mosyak, E. Pogrebnyak, L.P. Yarin, Heat transfer in micro-channels: Comparison of experiments with theory and numerical results, International Journal of Heat and Mass Transfer, 48 (2005) 5580-5601.

[21] P. Rosa, T. Karayiannis, M. Collins, Single-phase heat transfer in microchannels: the importance of scaling effects, Applied Thermal Engineering, 29 (2009) 3447-3468.

[22] C.B. Sobhan, S.V. Garimella, A comparative analysis of studies on heat transfer and fluid flow in microchannels, Microscale Thermophysical Engineering, 5 (2001) 293-311.

[23] P.-S. Lee, S.V. Garimella, D. Liu, Investigation of heat transfer in rectangular microchannels, International Journal of Heat and Mass Transfer, 48 (2005) 1688-1704.

[24] M. Rahimi, R. Mehryar, Numerical study of axial heat conduction effects on the local Nusselt number at the entrance and ending regions of a circular microchannel, International Journal of Thermal Sciences, 59 (2012) 87-94.

[25] G. Maranzana, I. Perry, D. Maillet, Mini-and micro-channels: influence of axial conduction in the walls, International Journal of Heat and Mass Transfer, 47 (2004) 3993-4004.

[26] V.V. Dharaiya, S.G. Kandlikar, Numerical Investigation of Heat Transfer in Rectangular Microchannels Under H2 Boundary Condition During Developing and Fully Developed Laminar Flow, Journal of Heat Transfer, 134 (2011) 020911-020911.

[27] G.L. Morini, Viscous Dissipation as Scaling Effect for Liquid Flows in Microchannels (Keynote), in: ASME 3rd International Conference on Microchannels and Minichannels, American Society of Mechanical Engineers, 2005, pp. 93-102.

[28] M.G. Mala, D. Li, J.D. Dale, Heat transfer and fluid flow in microchannels, International Journal of Heat and Mass Transfer, 40 (1997) 3079-3088.

[29] G.L. Morini, Single-phase convective heat transfer in microchannels: a review of experimental results, International Journal of Thermal Sciences, 43 (2004) 631-651.

[30] G.P. Celata, Heat transfer and fluid flow in microchannels, Boiling and evaporation, (2004).

[31] M.A. Oyinlola, G.S.F. Shire, Investigating Heat Transfer in Absorber Plates with Minichannels, in:

Christos N Markides, Andrew L Heyes, P.R. Childs (Eds.) 13th UK Heat Transfer Conference (UKHTC13), London, 2013, pp. 740-747.

[32] N. Sharma, G. Diaz, Performance model of a novel evacuated-tube solar collector based on minichannels, Solar Energy, 85 (2011) 881-890.

[33] D. Tondeur, Y. Fan, J.-M. Commenge, L. Luo, Flow and pressure distribution in linear discrete "laddertype" fluidic circuits: an analytical approach, Chemical Engineering Science, 66 (2011) 2568-2586.

[34] J.P. Holman, Experimental methods for engineers, McGraw-Hill/Connect Learn Succeed, Boston, 2012.

[35] H. Wu, P. Cheng, An experimental study of convective heat transfer in silicon microchannels with different surface conditions, International Journal of Heat and Mass Transfer, 46 (2003) 2547-2556. 